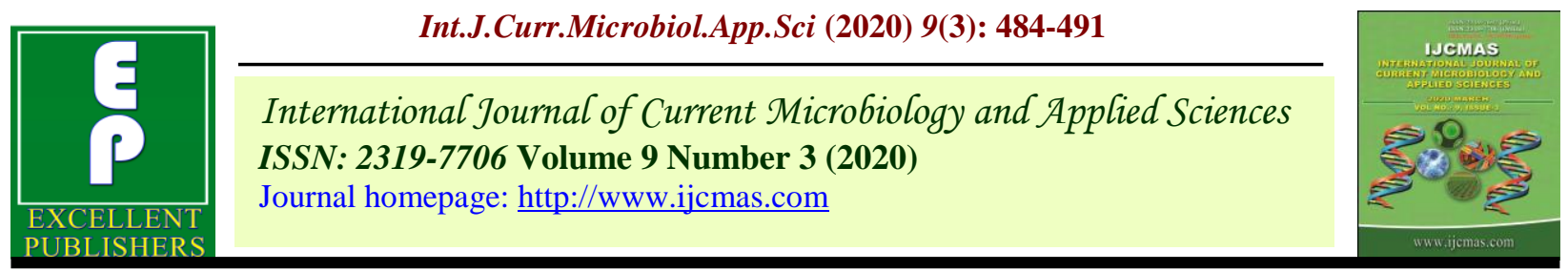

Original Research Article

https://doi.org/10.20546/ijcmas.2020.903.056

\title{
Knowledge of Ragi Growers towards Agricultural Technology Management Agency
}

\author{
V. Jagdeesh*, M. T. Lakshminarayan and R. Narayanareddy \\ Department of Agricultural Extension, College of Agriculture, \\ University of Agricultural Sciences, Bengaluru, Karnataka, India \\ *Corresponding author
}

\section{Ke y w ords}

Knowledge, Ragi growers, Extension activities, Characteristics

Article Info

Accepted:

05 February 2020

Available Online: 10 March 2020

\section{A B S T R A C T}

The present study was carried out in Kolar and Chikkaballapura districts of Karnataka state during 2018-2019 to assess the knowledge of ragi growers towards Agricultural Technology Management Agency (ATMA) and also to find out the extent of participation of ragi growers in the extension activities organized under ATMA. Ninety ragi growers who availed the benefits under ATMA were purposively selected for the study. The results revealed that a majority of beneficiary ragi growers $(72.23 \%)$ had medium to high level of overall knowledge regarding ATMA. It was found that more than half of the beneficiary ragi growers had participated in field visits (57.77\%), exposure visits (57.77\%), meetings/discussion $(51.11 \%)$ and demonstrations $(51.11 \%)$. Whereas, a majority of beneficiary ragi growers had not participated in extension activities such as: agricultural campaign (78.89\%), farm school (67.78\%), kissan gostis (farmersscientist's interaction) (64.45\%), district level exhibitions (57.78\%) and Krishi mela/fairs $(51.11 \%)$. Further, the results revealed that education, achievement motivation, management orientation, cosmopoliteness, innovativeness, mass media exposure, training on ATMA, extension agency contact and extension participation of beneficiary ragi growers had significant to highly significant association with their knowledge level regarding ATMA

\section{Introduction}

A Centrally Sponsored Scheme to provide support to State Extension Reforms was launched by Indian Council of Agricultural Research (ICAR) during 1998-1999. Agricultural Technology Management Agency (ATMA) was implemented in the country under the Innovation Technology Dissemination (ITD) component of National Agricultural Technology Project. ATMA is a registered society of key stakeholders involved in agricultural activities for sustainable agricultural development in the district. It is a focal point for integrating research and extension activities and 
decentralizing day-to-day management of agricultural extension system. ATMA is a centrally sponsored scheme which lends support to state extension programmes for extension reforms was launched by ICAR in 1999. This scheme is major initiative towards revitalizing agricultural extension in the states to make extension system decentralized and demand driven.

The scheme is implemented through autonomous district level institutions established in the states in the form of ATMA. The Joint Director of Agriculture of the concerned district acts as the project director of ATMA. The ATMA at district level would be increasingly responsible for all the technology dissemination activities at the district level. It would have linkage with all the line departments, research organizations, non-governmental organizations and agencies associated with agricultural development in the district. Research and extension units within the districts such as Zonal Research Stations (ZRS) or substations, Krishi Vigyan Kendras (KVKs) and the key line departments of Agriculture, Animal Husbandry, Horticulture and Fisheries etc. would become constituent members of ATMA. Each research- extension (R-E) unit would retain its institutional identity and affiliation but programmes and procedures concerning district-wise R-E activities would be determined by ATMA Governing Board to be implemented by its management committee (AMC). As a society, it would be able to receive and expend funds, entering into contracts and agreements and maintaining revolving accounts that can be used to collect fees and thereby recovering operating cost ATMA (Sahu et al., 2012). The knowledge of farmers on any project/programme is a prerequisite for taking benefits under programme/project. In this backdrop, thepresent study was conducted with the following specific objectives:
1. To assess the knowledge of beneficiary ragi growers towards ATMA

2. To find out the extent of participation of beneficiary ragi growers in the extension activities organized under ATMA

To find out the association between personal, socio-economic, psychological and communication characteristics of beneficiary ragi growers with their knowledge level towards ATMA.

\section{Materials and Methods}

The present study was carried out in Chikkaballapura and Kolar districts of Karnataka state during 2018-2019Undivided Kolar (Kolar and Chikkaballapura) district was one of the eight districts in Karnataka, where ATMA was first implemented in the state during 2005-2006. Hence, Kolar and Chikkaballapura districts were selected for the study. Ragi is the main staple crop cultivated in all the six taluks of Chikkaballapura district and five taluks of Kolar district, hence ragi crop was selected for the study. The major area under ragi was in Shidlaghatta taluk $(11,122$ ha) in Chikkaballapura district and Kolar taluk $(13,112$ ha) of Kolar district during 2017-2018. Hence, Shidlaghatta taluk from Chikkaballapura district and Kolar taluk from Kolar district was purposively selected for the study.

Ninety ragi growers (who had availed benefits under ATMA) from Shidlaghatta taluk of Chickaballapura district (45 Nos.) and Kolar taluk of Kolar district (45 Nos.) were randomly selected for the present study. Expost-facto research design was followed for the research study. Data was collected personally using a pre-tested interview schedule. 
Knowledge of ragi growers towards ATMA

Knowledge level in the present study is operationalized as the quantum of scientific information known to the ragi growers about the ATMA. Ten knowledge statements/items on special features and operative mechanism of ATMA were selected to assess the knowledge level of ragi growers. The test constituted ten knowledge questions which were provided with two alternative answers viz., 'correct answer' and 'incorrect answer'. The knowledge test was administered to the ragi growers and they were asked to choose among the alternatives. Quantification of knowledge item/answers was made by giving a score of 'one' and 'zero' for 'correct answer' and 'incorrect answers', respectively. The scores of all the ten knowledge items were summed up to get knowledge score of the ragi growers. The summation of scores for a particular respondent indicated his knowledge level about ATMA. The maximum score one would get was ten and the minimum score was zero. Based on the total score obtained for all the ten knowledge items, the ragi growers were classified into three categories namely, 'low', 'medium' and 'high' considering mean (5.50) and half standard deviation (0.68) as a measure of check.

\begin{tabular}{|c|c|c|}
\hline Category & Criteria & Score \\
\hline Low & $<($ Mean $-1 / 2$ SD $)$ & Below 4.82 \\
\hline Medium & $($ Mean $\pm 1 / 2 S D)$ & 4.82 to 6.18 \\
\hline High & $>($ Mean $+1 / 2$ SD $)$ & Above 6.18 \\
\hline
\end{tabular}

\section{Results and Discussion}

Specific knowledge of beneficiary ragi growers regarding ATMA

The results in Table 1 reveals that all the beneficiary ragi growers $(100.00 \%)$ had correct knowledge on the item, 'ATMA is implemented through agricultural department', whereas majority of the beneficiary ragi growers had correct knowledge on the items such as: Major activity of ATMA is transfer of technology on agriculture and allied aspects (88.88\%), Farmers friend serves as a vital link between extension system and farmers at village level $(68.88 \%)$, ATMA facilitates the involvement of private sector in providing agricultural inputs (66.66\%), Agricultural entrepreneurs supplement the efforts of extension workers by providing critical technical advice to farmers (65.55\%), District Farmers Advisory Committee provides farmers feedback for district level planning (56.66\%), Farmers organizations/Farmers interest groups will coordinate in organizing demonstrations, onfarm trials and give feedback to extension and research $(56.66 \%)$,Farm school will serve as a mechanism for farmer to farmer extension (56.66\%),ATMA facilitates the availability of credit to resource poor and marginal farmers, particularly SC/ST/women farmers $(55.55 \%)$ and ATMA follows bottom up planned procedure by considering farmers input into programme $(51.11 \%)$. Frequent contact with the extension agency and participation in extension activities including training programmes has helped the respondents in gaining knowledge regarding ATMA.

\section{Overall knowledge of beneficiary ragi growers regarding ATMA}

A bird eye view of Table 2 reveals that 36.68 per cent of the beneficiary ragi growers had high level of overall knowledge regarding ATMA, while 35.55 and 27.77 per cent of the beneficiary ragi growers had medium and low level of overall knowledge regarding ATMA, respectively. It can be inferred that a majority of beneficiary ragi growers $(72.23 \%)$ had medium to high level of overall knowledge regarding ATMA. The reasons mentioned in 
specific knowledge items also holds-good here also for majority $(72.23 \%)$ of beneficiary ragi growers possessing medium to high level of overall knowledge regarding ATMA. Similar findings were reported by Kenchanagouder (2007) and Prakash and Deepak De (2009).

Participation of beneficiary ragi growers in the extension activities organized under ATMA

It is observed from Table 3 that a majority of beneficiary ragi growers had participated in field visits $(57.77 \%)$, exposure visits $(57.77 \%)$, meetings/discussion $(51.11 \%)$ and demonstrations (51.11\%). Whereas, a majority of beneficiary ragi growers had not participated in extension activities such as: agriculturalcampaign (78.89\%), farm school (67.78\%), kissan gostis (farmers-scientist's interaction) (64.45\%), district level exhibitions (57.78\%) and Krishi mela/fairs $(51.11 \%)$. It is disheartening to note that a majority of beneficiary ragi growers had not participated in extension activities such as: agricultural campaign, farm school, kissan gostis (farmers-scientist's interaction), district level exhibitions and Krishi mela /fairs. Lack of knowledge on the date, time and venue of extension activities and lack of free time to participate in extension activities are the reasons for beneficiary ragi growers for not participating in the extension activities organized under ATMA by the Agricultural department.

\section{Association between personal, socio- economic, psychological and communication characteristics of beneficiary ragi growers with their knowledge level towards ATMA}

Table 4 presents the data on the association between personal, socio-economic, psychological and communication characteristics of beneficiary ragi growers with their knowledge regarding ATMA. The results revealed that variables such as, age, family size, annual income, land holding and farming experience had no association with the knowledge level of beneficiary ragi growers regarding ATMA, whereas variables such as achievement motivation, management orientation, cosmopoliteness, and mass media exposure of beneficiary ragi growers had significant association with their knowledge level on ATMA at five per cent level. Education, innovativeness, training on ATMA, extension agency contact and extension participation of beneficiary ragi growers had highly significant association with their knowledge level regarding ATMA at one per cent level.

It is observed from Table 4 that 69.90 per cent of the variation in the knowledge level of beneficiary ragi growers was explained by the 14 personal, socio-economic, psychological and communication characteristics selected for the research study as evidenced by $\mathrm{R}^{2}$ value of 0.6990.More or less similar results were reported by Banerjee (1976), Prakash and Deepak De (2005), Lakshminarayan et al., (2013) and Prabuilliger et al., (2017).

The explanation for the personal, socioeconomic, psychological and communication characteristics of beneficiary ragi growers having significant to highly significant association with the knowledge level regarding ATMA is discussed in the following paragraphs.

Education of an individual provides an opportunity for the farmers to expose themselves to mass media (radio, television, newspaper etc.), which carry messages on the special features and benefits of ATMA programme. Achievement motivation is the important determinant of excellence or perfection in what one does. 
Table.1 Specific knowledge of beneficiary ragi growers regarding ATMA ( $\mathrm{n}=90)$

\begin{tabular}{|c|c|c|c|c|c|}
\hline \multirow{3}{*}{$\begin{array}{l}\text { Sl. } \\
\text { No. }\end{array}$} & \multirow[t]{3}{*}{ Knowledge items } & \multicolumn{4}{|c|}{ Beneficiaries ragi growers } \\
\hline & & \multicolumn{2}{|c|}{ Correct knowledge } & \multicolumn{2}{|c|}{ Incorrect knowledge } \\
\hline & & Number & Per cent & Number & Per cent \\
\hline $\mathbf{1}$ & $\begin{array}{l}\text { ATMA is implemented through } \\
\text { agricultural department }\end{array}$ & 90 & 100.00 & 0 & 0.00 \\
\hline 2 & $\begin{array}{l}\text { Major activity of ATMA is transfer } \\
\text { of technology on agriculture and } \\
\text { allied aspects }\end{array}$ & 80 & 88.88 & 10 & 11.12 \\
\hline 3 & $\begin{array}{l}\text { ATMA follows bottom up planned } \\
\text { procedure by considering farmers } \\
\text { input into programme }\end{array}$ & 46 & 51.11 & 44 & 48.89 \\
\hline 4 & $\begin{array}{l}\text { ATMA facilitates the availability of } \\
\text { credit to resource poor and marginal } \\
\text { farmers, particularly SC/ST/women } \\
\text { farmers }\end{array}$ & 50 & 55.55 & 40 & 44.45 \\
\hline 5. & $\begin{array}{l}\text { District Farmers Advisory } \\
\text { Committee provides farmers } \\
\text { feedback for district level planning }\end{array}$ & 51 & 56.66 & 39 & 43.34 \\
\hline 6. & $\begin{array}{l}\text { Agricultural entrepreneurs } \\
\text { supplement the efforts of extension } \\
\text { workers by providing critical } \\
\text { technical advice to farmers }\end{array}$ & 59 & 65.55 & 31 & 34.45 \\
\hline 7 & $\begin{array}{l}\text { Farmers friend serves as a vital link } \\
\text { between extension system and } \\
\text { farmers at village level }\end{array}$ & 62 & 68.88 & 28 & 31.12 \\
\hline 8. & $\begin{array}{l}\text { Farm school will serve as a } \\
\text { mechanism for farmer to farmer } \\
\text { extension }\end{array}$ & 51 & 56.66 & 39 & 43.34 \\
\hline 9. & $\begin{array}{l}\text { Farmers organizations/Farmers } \\
\text { interest groups will co-ordinate in } \\
\text { organizing demonstrations, on-farm } \\
\text { trials and give feedback to extension } \\
\text { and research }\end{array}$ & 51 & 56.66 & 39 & 43.34 \\
\hline 10 & $\begin{array}{l}\text { ATMA facilitates the involvement of } \\
\text { private sector in providing } \\
\text { agricultural inputs }\end{array}$ & 60 & 66.66 & 30 & 33.34 \\
\hline
\end{tabular}

Table.2 Overall knowledge level of beneficiaries towards ATMA $(n=90)$

\begin{tabular}{|c|c|c|c|}
\hline \multirow{2}{*}{$\begin{array}{c}\text { Sl . } \\
\text { No. }\end{array}$} & Knowledge category & \multicolumn{2}{|c|}{ Beneficiary ragi growers } \\
\cline { 3 - 4 } & & Number & Per cent \\
\hline $\mathbf{1}$ & Low (, 4.82 score) & 25 & 27.77 \\
\hline $\mathbf{2}$ & Medium (4.82 to 6.18 score) & 32 & 35.55 \\
\hline $\mathbf{3}$ & High ( > 6.82 score) & 33 & 36.68 \\
\hline & Total & 90 & 100.00 \\
\hline
\end{tabular}


Table.3 Participation of beneficiary ragi growers in the extension activities organized under ATMA $(n=90)$

\begin{tabular}{|c|c|c|c|c|c|}
\hline \multirow[t]{3}{*}{ SI. No. } & \multirow{3}{*}{ Extension activities } & \multicolumn{4}{|c|}{ Beneficiary ragi growers } \\
\hline & & \multicolumn{2}{|c|}{ Participation } & \multicolumn{2}{|c|}{ Non participation } \\
\hline & & No. & Per cent & No. & Per cent \\
\hline $\mathbf{1}$ & Meetings/Discussion & 46 & 51.11 & 44 & 48.89 \\
\hline 2 & Field visits & 52 & 57.77 & 38 & 42.23 \\
\hline 3 & Demonstration & 46 & 51.11 & 44 & 48.89 \\
\hline 4 & Field days & 44 & 48.89 & 46 & 51.11 \\
\hline 5 & Farm school & 29 & 32.22 & 61 & 67.78 \\
\hline 6 & Exposure visits & 52 & 57.77 & 38 & 42.23 \\
\hline 7 & Krishi melas/fairs & 44 & 48.89 & 46 & 51.11 \\
\hline 8 & District level exhibitions & 38 & 42.22 & 52 & 57.78 \\
\hline 9 & $\begin{array}{c}\text { Kissan gostis } \\
\text { (Farmers - scientists interaction) }\end{array}$ & 32 & 35.55 & 58 & 64.45 \\
\hline 10 & Agricultural campaign & 10 & 11.11 & 80 & 78.89 \\
\hline
\end{tabular}

Table.4 Association between personal, socio-economic, psychological and communication characteristics of beneficiary ragi growers with their knowledge regarding ATMA $(n=90)$

\begin{tabular}{|c|c|c|c|c|c|}
\hline $\begin{array}{l}\text { Sl. } \\
\text { No. }\end{array}$ & Characteristics & $\begin{array}{c}\text { Chi-square } \\
\text { value }\end{array}$ & $\begin{array}{l}\text { Regression } \\
\text { co-efficient }\end{array}$ & $\begin{array}{l}\text { Standard } \\
\text { error of } \\
\text { regression } \\
\text { co-efficient }\end{array}$ & $\begin{array}{c}\text { 't' } \\
\text { value }\end{array}$ \\
\hline 1 & Age & $3.27^{\mathrm{NS}}$ & 0.41 & 0.38 & $0.92^{\mathrm{NS}}$ \\
\hline 2 & Education & $10.11^{* *}$ & 0.11 & 0.36 & $3.27^{* *}$ \\
\hline 3 & Family size & $5.67^{\mathrm{NS}}$ & 0.51 & 0.39 & $0.76^{\mathrm{NS}}$ \\
\hline 4 & Annual income & $6.11^{\mathrm{NS}}$ & 0.42 & 0.20 & $0.47^{\mathrm{NS}}$ \\
\hline 5 & Land holding & $3.99^{\mathrm{NS}}$ & 0.41 & 0.36 & $0.87^{\mathrm{NS}}$ \\
\hline 6 & Farming experience & $4.86^{\mathrm{NS}}$ & 0.56 & 0.41 & $0.93^{\mathrm{NS}}$ \\
\hline 7 & $\begin{array}{l}\text { Achievement } \\
\text { motivation }\end{array}$ & $10.19^{*}$ & 0.36 & 0.86 & $2.38^{*}$ \\
\hline 8 & $\begin{array}{c}\text { Management } \\
\text { orientation }\end{array}$ & $11.69^{*}$ & 0.42 & 0.89 & $2.11^{*}$ \\
\hline 9 & Innovativeness & $14.60^{* *}$ & 0.28 & 0.81 & $2.89^{*}$ \\
\hline 10 & Cosmopoliteness & $9.51^{*}$ & 0.22 & 0.10 & $2.20^{*}$ \\
\hline 11 & Mass media exposure & $10.23^{*}$ & 0.39 & 0.86 & $2.20^{*}$ \\
\hline 12 & Training on ATMA & $15.66^{* *}$ & 0.11 & 0.36 & $3.27^{* *}$ \\
\hline 13 & $\begin{array}{l}\text { Extension agency } \\
\text { contact }\end{array}$ & $17.86^{* *}$ & 0.10 & 0.38 & $3.80^{* *}$ \\
\hline 14 & Extension participation & $16.89^{* *}$ & 0.13 & 0.42 & $3.23^{* *}$ \\
\hline
\end{tabular}

NS=Non-significant, $*=$ Significant at $5 \%$ level, $* *=$ Significant at $1 \%$ level; $\mathrm{R}^{2}=0.699$ 
It forces the individual towards reaching the goals which he/she has to set for himself. The farmers have excelled in agriculture in knowing and obtaining the benefits of the ATMA by contacting extension functionaries and participating in extension activities. The farmers are inculcated the managerial abilities through extension activities (meetings/discussion, training programmes, field visits, demonstrations, exposure visits, farm school etc.) conducted by the extension personnel organized under ATMA.

Farmers try to seek more information and adopt agricultural innovations disseminated through ATMA implemented by Karnataka State Department of Agriculture. Obviously, the farmers will contact extension functionaries to know more about ATMA. A cosmopolite farmer during his visit to offices of agricultural extension personnel, which are located at Hobli/ Taluk/ District, might have seen the display of information on ATMA. He might have interacted with the agricultural extension personnel regarding the procedure of getting benefits under ATMA.

Higher level of mass media exposure has facilitated the beneficiary ragi growers to develop habits of gathering information about ATMA implemented by the Department of Agriculture. The trainees who had attended trainings on ATMA might have been taught by the trainers about the importance, special features, cafeteria of activities and benefits of ATMA. Agricultural extension professionals not only communicate about the latest farm technologies to the farmers, but they also inform the farmers about various agricultural or extension programmes/schemes /reforms implemented by State Department of Agriculture.

Participation in extension activities such as, group discussion, demonstrations, training programmes, field days, farmers field school,
Krishi melas, etc., organized under ATMA, would promote in gaining knowledge among farmers regarding the scope and benefits for farmers in ATMA.

The results of the present study have revealed that as high as 72.23 of the ragi growers had medium to high level of knowledge regarding ATMA. Further, it was found that education, achievement motivation, management orientation, cosmopoliteness, innovativeness, mass media exposure, training on ATMA, extension agency contact and extension participation of beneficiary ragi growers had significant to highly significant association with their knowledge level regarding ATMA.

The farmers should regularly contact the extension personnel and participate actively in the extension activities for increasing their knowledge about ATMA for deriving optimum benefits from the programme. Mass media like radio, television, internet, magazines, newspaper etc., should also carry messages on the benefits of ATMA for enhancing the knowledge of farmers for effective utilization of benefits under ATMA.

\section{References}

Banerjee,S. K., 1976, A study of socio economic and demographic factors associated to the knowledge of agriculture technology among tribal farmers of Bastar district of Chattisgarh, M.Sc. (Agri.), Thesis (Unpub,), College of Agriculture, Jabalpur

Kenchanagouder,S. M., 2007, An analytical study on Sampoorna Grameen Rozgar Yojana in Gadag district of Karnataka State. M.Sc. (Agri.), Thesis (Unpub.), Univ. Agric. Sci., Dharwad

Lakshminarayan, M.T., Banuprakash,K.G, Shankaranaryana.V, and Jahir pasha, C.R., 2013, Knowledge and symbolic adoption of trained sericulturists, 
Mysore J. Agri. Sci.,47 (1): 152-157

PrabhuIlliger, Narasimha, N. and Lakshminarayan, M.T., 2017, Attitude of farmers towards cultivation of $\mathrm{Bt}$ cotton, Mysore J.Agri. Sci.,51 (4): 860865

Prakash, S. and Deepak De, 2009, A study on institutional innovations in technology dissemination: A world bank assisted project, Journal of Global Communication 23(2):17-18

Sahu,B.P., Chaturvedi,M.K., ShusmaSahuyadav,K., 2012, Knowledge level of beneficiaries towards the activities of ATMA. Agric. Update, 7 (3\& 4): 319-322.

\section{How to cite this article:}

Jagdeesh. V, M. T. Lakshminarayan and Narayanareddy. R. 2020. Knowledge of Ragi Growers towards Agricultural Technology Management Agency. Int.J.Curr.Microbiol.App.Sci. 9(03): 484-491. doi: https://doi.org/10.20546/ijcmas.2020.903.056 